\title{
An Evaluation of the Ability of RFID Tags to Withstand Distribution of Fresh Produce in the RPC Pooling System
}

\author{
By J. Singh, ${ }^{*}$ S. P. Singh,2 K. Desautels,1 K. Saha2 and E. Olsen 1 \\ 1Industrial Technology, Cal Poly State University, San Luis Obispo, CA 93407, USA \\ ${ }_{2}$ School of Packaging, Michigan State University, East Lansing, MI 48824, USA
}

\begin{abstract}
SUMMARY
This study focused on the ability of radio frequency identification (RFID) tags applied on reusable plastic containers (RPCs) to withstand repeated abuse due to physical distribution and storage environment related hazards. It also studied the effect of the chemical cleaning environments that RPCs are commonly exposed to in the pooling/rental systems commonly used to distribute fresh produce. RPCs are being successfully deployed in the US, Europe and Asia to ship fresh produce from growers to retailers. The increasing demand for traceability and tracking of fresh produce from 'farm to fork' requires these containers to be monitored and identified in the food supply chain, and RFID technology provides one of the solutions. This study compared eight commercially available RFID tags mounted on RPCs for use in fresh produce distribution and subjected them to repeated physical and climatic cycles representing the distribution and cleaning environments, and their effective 'read' capabilities were tested.
\end{abstract}

\section{INTRODUCTION}

Radio frequency identification (RFID) has generated much interest ever since Wal-Mart announced its initiative to implement RFID technology in its supply chain in 2003.1 This started a series of initia-tives among other major retailers, such as Albertsons, Metro and Target.1 Almost concurrently, the Department of Defense took the initiative to implement RFID technology in its Defense Logistics Agency (DLA) supply chain.1 Over the past decade, the cost reduction in RFID technology, collectively with improvements in performance and global standards, has enabled its widespread use in the logistical planning and operation of supply chain processes in the manufacturing, distribution and retail industries.

RFID involves the use of electronic tags with integrated circuit chips that can store data. The tags, affixed to the asset, transmit their data via low power radio waves to reading systems that are tuned to the same frequency, enabling transactions to be recorded and tracked. A typical transmission sequence consists of a system handshake, data modulation and data encoding. 2 A form of RFID tags includes battery powered tags (or 'active'), but 'passive' (or 'backscatter') tags are slated to be more widely used. Tags in this category derive all their power from the reader's signal. Nearly all RFID systems operate on one of four frequency bands, namely low frequency (125-134 kHz), high fre-quency 
(13.553-13.567 MHz), ultra high frequency (UHF, 400-1000 MHz) and microwave (2.45 GHz).2 The read range typically increases with increase in frequency. Low frequencies are commonly adopted for applications such as livestock tracking, card key, and access control. High-frequency RFID is more flexible and is utilized for applications such as baggage handling. UHF is the most widely used RFID band due to its robustness and read range. Key applications for the UHF band are materials management and supply chain tracking. The microwave band features in applica-tions such as electronic toll collection and railroad monitoring.

The application of RFID technology as related to packaging, although widely adopted, is still fraught with performance concerns. 3 The optimum performance of this combination depends on many factors, such as environmental, geometry of the product/package and packaging materials and/or packaged product.4 A recently published review paper highlights several consumer-level RFID appli-cations and initiatives taken by some of the global leaders in the apparel, consumer goods and fresh produce industries. 5 This research highlights the promise of this technology to provide end-to-end real-time visibility of all items moving through the supply chain. Several other studies have evaluated topics ranging from readability issues, tag orientation and location, effect of product type and packag-ing, among others.

A recently published study evaluating the effects of item composition, tag inlay design, reader antenna polarization, power and transponder orientation on the dynamic coupling effi ciency of back-scatter UHF RFID concluded that the use of this technology for item-level identification of food requires multi-parameter assessment beforehand.6 It was found that the effect of water content was far more significant than metallized packaging; tag placement in relation to the packaging material was significant in relation to coupling capabilities; reader antenna polarization was signifi cant with circular polarization being better than linear polarization at tag detection; and the tag inlay design was significant in relation to the coupling capabilities of the RFID system.

A study focusing on RFID tag orientation and package contents was conducted by Clarke et al., and revealed that only $25 \%$ of the tags on a pallet load of shipping containers holding bottled water could be effectively read, whereas dry rice filled jars had a higher read at $80.6 \% .7$ The study concludes that it is difficult to achieve $100 \%$ reads even with empty boxes. This suggests the limitation of implementing passive RFID tags on packages with certain types of contents. The study that used Class 1 Gen 1 tag technology did not discover a significant effect based on tag orientation.

A separate recent study considered package content, tag location, fork lift speed, pallet pattern and their interaction as the variables. 8 It was observed that readability greatly varies for different product-package systems. A pallet load of paper towels produced near $100 \%$ readability rates followed by bottled water and carbonated soda cans. It was observed that slower forklift truck speeds provided better tag readability. The best pallet patterns for tag readability were dependent on the product-package type. The best pallet pattern for bottled water was column stack and that for carbonated soda was interlocking.

The effect of conveyer belt speeds on the readability of tagged cases of consumer 
products was observed in a recent research.9 Conveyer belt speeds of 61, 122 and 183 $\mathrm{m} / \mathrm{min}$ were used in this study to analyse the readability of tagged cases of paper towels, bottled water and carbonated bever-age cans. The study concluded that besides the paper towel cases, the conveyer belt speed had a considerable effect on the read rates of the tagged cases.

Another study evaluated the effect of moving palletized loads of the same tagged consumer product cases, as in the above-mentioned research, through a warehouse portal at speeds of $1.6,8.1$ and $16.1 \mathrm{~km} / \mathrm{h}$, respectively.10 It was observed that fork truck operating speeds had very little effect on read rates. Speeds over $15 \mathrm{~km} / \mathrm{h}$ reduced the tag read rates by about $10 \%$ as compared to slower speeds of around $2 \mathrm{~km} / \mathrm{h}$.

Although a limited amount of published research is available on readability, orientation, location, product/package system, etc., none has delved on the RFID tag durability. Reusable plastic containers (RPCs) are being widely used in the automotive and fresh produce industries. First introduced to the US retail trade in 1996 by Wal-Mart and HEB (Texas-based retailer), RPCs have become prevalent at all major retail outlets.11 Recent deployment of these reusable containers has been conducted at Stater Bros. (2006), Kroger (2006), Harris Teeter (2008), etc.11

With the recently reinvigorated environmental stewardship goals set in place by most consumer goods manufacturers and distributors, the employment of RPCs has been rapidly growing in the packaging industry. A recent Life Cycle Inventory study comparing RPCs with single-use display-ready paper corrugated trays summarized its findings as follows: the RPCs require 39\% less total energy, produce $95 \%$ less total solid waste and generate $29 \%$ less total greenhouse gas emissions. 12

RFID technology promises to provide unrealized benefits when applied to RPCs, provided the tag is able to survive multiple trips during distribution. Therefore, the study of the durability and reuse of RFID tags on RPCs is of great importance to meet the supply chain distribution and sanitation requirements for fresh produce. A recent report on the deployment of RFID tags designed for single use could be used in multiple-use scenarios without significant deterioration in performance if posi-tioned optimally on RPCs.13

RPCs are typically leased or rented through a third-party pooling system for distribution by the manufacturing, distribution and retail industries. They are usually sent to the growers, who in turn fill them and send them to the distribution centres/retailers. The retailers, who often use the fi lled RPCs directly for display, are not generally responsible for the rental amount or lost RPCs; the growers are. Figure 1 describes the pooling system approach commonly used by the fresh produce industry. As can be seen in the figure, in addition to repeated transportation and handling cycles, any RFID tags along with the containers undergo repeated stress due to high temperature washing with chemical detergents (sanitization), all of which impact the 'read' capabilities of RFID tags.

MATERIALS AND METHODS 
The distribution testing protocol established for this study was adopted from test methods/procedures proposed by the American Society for Testing and Materials (ASTM)14 and International Safe Transit Association (ISTA).15 The protocol was developed to determine the ability of several types of RFID tags placed on RPCs to withstand the abuse of industrial distribution and sanitization for fresh produce applications. The purpose of this project was to evaluate the readability of the tags after being sub-jected to the anticipated hazards and conditions through a series of laboratory-simulated shipping cycles. Five shipping cycles were conducted on eight types of RFID tags on the same RPC type. All eight tags were placed on 10 RPCs providing 10 replicates for each simulated distribution cycle. The details of the test methodology for this study are described in the section Testing Procedure.

\section{Reusable plastic containers}

The RPCs for this study were obtained from Polymer Logistics Inc., (Riverside, CA, USA). Model 6416 (Figure 2) was used for this study, which measures $60 \times 40 \times 6.5 \mathrm{~cm} 3$ with a nesting height of $33 \mathrm{~mm}$ and tare weight of $1.50 \mathrm{~kg}$. The injection-moulded RPCs were made of polypropylene and had a recommended load capacity of $15 \mathrm{~kg}$.

\section{RFID tags and hardware}

The following eight UHF Class 1 Gen 2 tags were used in this study (Figure 3). The detailed speci-fications for the tags are available from the distributor's website.16

- Intermec IT65 large

- Intermec IT65 small

- Alien 9450

- Laminated Alien 9450

- Alien 9554

- Laminated Alien 9554

- Alien 9654

- Laminated Alien 9654

These tags were elected because they are specified to provide the optimal performance in conjunction with RPCs or environments containing water and metal.

The encapsulated Intermec (Everett, WA, USA) tags are rated to perform in harsh industrial appli-cations and temperatures ranging from -40 to $121^{\circ} \mathrm{C}$. The Alien Technology (Morgan Hill, CA, USA) tags (non- laminated) used the Fasson ${ }^{\circledR}$ S490 inlay adhesive, a general purpose permanent adhesive. 17 The Alien tag models 9450, 9554 and 9654 were also laminated on both sides using Xyron Inc.'s (Scottsdale, AZ, USA) 22 $\mathrm{cm}$ ezLaminator lamination machine. No heat was used to laminate the $0.08 \mathrm{~mm}$ thick polyethylene film to the tags. To attach the laminated and encapsulated tags to the RPCs, $2.54 \mathrm{~cm}$ wide and $3.18 \mathrm{~mm}$ thick double-sided 3M (St. Paul, MN, USA) model 4408 foam tape was used.

Alien Technology's Alien 9900 Gen 2 Enterprise RFID reader and ALR-961 1-CR 
circular polarized antenna were used in this study.17 Alien Gateway 10.1.1.10 middleware was used to collect all data. All tests were performed at $0 \%$ attenuation of the reader. Four ALR-961 1 circular polarized antennas were used since they are less sensitive to the tag orientation and sufficed the read distance require-ments for this project. The portal used in this project is shown in Figure 4.

\section{Testing procedure}

A simulation of the physical and climatic distribution environment for typical fresh produce shipments in a RPC pooling environment was conducted. The failure criteria adopted for this simulation were functional damage to the RPCs, RFID tags dislodging from the RPCs or fatal damage to the RFID tags, whichever occurred first. The surviving RPCs and tags were continued through the simulation until 10 cycles were completed. With the eight types of tags applied on a set of 10 RPCs, a total of 80 RPC-tag combinations were included in this research. Figure 5 below summarizes the simulated environment for this research.

Refrigerated conditioning. Tagged containers were conditioned for $48 \mathrm{~h}$ at a temperature of $5^{\circ} \mathrm{C}\left( \pm 2^{\circ} \mathrm{C}\right)$ and relative humidity of $85 \%( \pm 5 \%)$, as specified by ASTM D4332 for each distribution test cycle.14

Vibration testing. The sinusoidal vibration test, also known as the 'sweep and dwell' vibration test, was employed as per ASTM D999.14 This test is typically used to assess the performance of a container, with its interior packing and means of closure, in terms of both its strength and of the protection it provides its contents when it is subjected to vibration such as it experiences in transporta-tion.14 It is not intended for determining the response of products to vibration for product design purposes.

Ten tagged and loaded RPCs were secured in a column pattern on a Lansmont model 1800 electro-hydraulic vibration tester (Lansmont Corp., Monterey, CA, USA), and a frequency 'sweep' from 3 to $100 \mathrm{~Hz}$ was performed to identify the resonant frequency where the maximum vertical displacement of the packages is observed. The vibration test setup is shown in Figure 6. The sinusoidal frequency identified through this test was $4.3 \mathrm{~Hz}$, at which it 'dwelled' for 15 min. The peak amplitude ( 0 peak) for this test was held steady at $0.5 \mathrm{~g}$ throughout the test. Figure 6 shows the simulated vibration test.

Drop testing. The filled containers were subjected to six drops representing one cycle in accordance with Schedule A, Handling - Manual and Mechanical, ASTM D4169.14 The RPCs were fi lled with simulated loads of $15 \mathrm{~kg}$, representing the maximum recommended shipping weight by the manufac-turer. The RPCs were tested based on the total container weight as described in ASTM D5276 at assurance level I. The drop height selected for all drops was $53.3 \mathrm{~cm}$. The drop sequence consisted of the following sequence: one drop on the bottom face, two drops on the adjacent bottom edges, two drops on the diagonally opposite bottom corners and one drop on the bottom face.

Sanitization process. Reusable containers such as RPCs, when used for fresh produce distribution, need to be cleaned and sanitized (often with a dilute chlorine or bleach solution) by a documented procedure before reuse to remove decay-causing organisms and 
sand and dirt that can injure the product. 18

After a set of conditioning, vibration and drop tests representing simulated distribution, an industrial wash cycle was performed in order to evaluate the post-wash performance. A Manitowoc Foodservice (New Port Richey, FL, USA) TempStar model doortype industrial dishwashing machine was employed for washing, rinsing and drying of the tagged RPCs. The erected RPCs were sanitized one at a time in this machine using Palm Plus Dishwashing liquid soap (Colgate-Palmolive Company, New York, NY, USA). The wash cycle, rinse time and dwell time for this process were 45, 11 and $2 \mathrm{~s}$, respectively. The operating temperatures for washing and rinsing were $66^{\circ} \mathrm{C}$ and $75^{\circ} \mathrm{C}$, respectively.

Tag readability testing. Upon completion of both the simulated distribution and sanitization wash cycles, as described in Figure 5, the RPCs were tested for tag readability. A pallet loaded with the tagged RPCs was moved through the portal with reader antennas on both sides at a speed of $8.05 \mathrm{~km} / \mathrm{h}$. The reads were scored on a 'read' or 'no read' basis. At each stage, the pallet was passed through two different times, first with the RPCs facing in one direction and then rotated $90^{\circ}$. This was done because the tags were placed on both the small faces of the RPCs. Five cycles of the distribution and sanitization protocol were conducted.

\section{RESULTS AND DISCUSSION}

A total of 80 tags were processed and tested through fi ve distribution and sanitization cycles, each as described in the section Testing Procedure. A complete report of the survival data is shown in Table 1 . Tags are designated as encapsulated (Intermec IT $65 \mathrm{~L}$ and Intermec IT65 S), laminated (ALN 9450, ALN 9554 and ALN 9654) or non-laminated (ALN 9450, ALN 9554 and ALN 9654) in the table, and the same designations are used through the discussion. There were two failure modes recorded during testing. Tags either became separated from the container (lost tag) or became unread-able. Lost tags were dropped from further testing. None of the encapsulated units $(n=20)$ failed for readability or lost tags during testing.

None of the laminated tags were lost during testing. For non-laminated tags $(n$ $=30$ ), $76.7 \%$ of the tags tested fell off by the end of the fifth wash cycle. Only $3.33 \%$ $(1 / 30)$ failed by the end of the second wash cycle. The third wash cycle saw a significant increase to $20 \%$ lost tags (Figure 7). For non-laminated tags, there seemed to be no significant relationship between specific tag numbers and tag retention.

With respect to readability, only $6.7 \%(2 / 30)$ of the laminated units failed for readability during all testing (Table 2 ). None of the laminated units failed for readability until the fourth wash cycle.

Of the non-laminated tags that were not lost, $33.3 \%$ were unreadable by the end of the third wash cycle (Table 3). The reduced percentage for the fourth and fifth wash cycles is misleading because $76.7 \%$ of the tags had fallen off by the fifth wash cycle. The starting number of non-laminated tags was 30 . The percentages shown in Table 3 are based on the number of remaining (not lost) tags.

Most read failures occurred after sanitization. There were only two instances where 
tags failed for readability after distribution stress. These were both non-laminated tags, and the failures occurred in cycles 1 and 3 (Table 1). The failure of one of the ALN 9450 tags directly after the first distribution stress (cycle 1) may be indicative of an early quality failure rather than totally stress related.

Overall, the data show that encapsulation is the most reliable method for protecting RFID tags. Lamination is a viable protection method, especially if the number of sanitization cycles is limited. Unlaminated tags suffered extensively from both failure modes during testing. The unlaminated tags tested are not viable for use in RPC pooling systems.

\section{CONCLUSIONS}

- All RFID tags evaluated can be read after the first cycle of physical, climatic and chemical han-dling for shipping and sanitation.

- Drops, vibration, high temperature washing and detergents collectively degrade the RFID tag identification capability when reused.

- Only three of the eight RFID tags that were commercially available at the time of this study survived more than ten cycles of reusability when subjected to shipping and cleaning require-ments for fresh produce.

- In general, the process of sanitization (chemical and climatic) is more detrimental to tag read-ability as compared with transportation and handling (physical).

- The ideal protection method for reuse of RFID tags on reusable containers is by encapsulation of the tag.

\section{ACKNOWLEDGEMENT}

The authors would like to acknowledge the support and funding provided by the Consortium for Packaging Technology and Science at California Polytechnic State University in making this research possible.

\section{REFERENCES}

1. Hunt VD, Puglia A, Puglia M. RFID - A Guide to Radio Frequency Identification. Wiley: New York, NY, 2007. 2. Haley CK, Jacobsen LA, Robkin S. Radio Frequency Identification Handbook for Librarians, Greenwood Publishing Group, Inc.: Santa Barbara, CA, 2007.

3. Finkenzeller K. RFID Handbook: Radio-Frequency Identification Fundamentals and Applications, Wiley: New York, NY, 1999.

4. Chau TC, Welt BA, Eisentadt, WR. Analysis and characterization of transponder antenna for radio frequency identifi cation (RFID) systems, Packaging Technology and Science 2006; 19: 33-44.

5. Singh SP, McCartney M, Singh J, Clarke R. Rfid research and testing for packages of apparel, consumer goods and fresh produce in the retail distribution environment. Packaging Technology and Science 2008; 21(2): 9 1-102.

6. McCarthy U, Ayalew G, Butler F, McDonnell K, Ward S. The effects of item composition, tag inlay design, reader antenna polarization, power and transponder orientation on the dynamic coupling efficiency of backscatter ultra-high frequency radio frequency identifi cation. Packaging Technology and Science 2009; 22(4): 24 1-248. 
7. Clarke R, Twede D, Tazelar J, Boyer K. Radio frequency identification (RFID) performance: the effect of tag orientation and package content. Packaging Technology and Science 2006; 19(1): 45-54.

8. Singh J, Olsen E, Vorst K, Tripp K. RFID tag readability issues with palletized loads of consumer goods. Packaging Technology and Science 2009; 22(8): 431-441.

9. Singh J, Deupser C, Olsen E, Singh SP. An examination of the variables affecting RFID tag readability in a conveyer belt environment. Journal of Applied Packaging Research 2007; 2(2): 61-73.

10. Singh J, Holtz R, Singh SP, Saha K. Effect of unitization and product types on readability of tagged packages of consumer goods. Journal of Applied Packaging Research 2008; 2(3): 179-189.

11. IFCO. Reusable plastic containers - a better way to ship produce. 2008;

http://www.ftsla.org/publicationsPress/

Bostonj01608_Presentations/ReusblPlstcContainersjFCO.Slate.pdf [accessed 13 October 2009].

12. Singh SP, Chonhenchob V, Singh J. Life cycle inventory and analysis of re-usable plastic containers and display-ready corrugated containers used for packaging fresh fruits and vegetables. Packaging Technology and Science 2006; 19(5): 279-293.

13. Reusable Packaging association. RFID study completed. 2009; http://www.choosereusables.org/ [accessed 13 October 2004].

14. ASTM Standards on Disc, Volume 15.10. ASTM International. http://www.astm.org/. West Conshohocken, PA, USA.

15. ISTA Procedures. http://www.ista.org/. East Lansing, MI, USA. [accessed 13 October 2009].

16. RFIDSupplyChain.com. http://www.rfidsupplychain.com/StoreFront.bok [accessed 14 October 2009].

17. Alien Technology Corporation. http://www.alientechnology.com/ [accessed 14 October 2009].

18. Tebbutt G, Bell V, Aislabie, J. Verification of cleaning efficiency and its possible role in programmed hygiene inspections of food businesses undertaken by local authority offi cers. Journal of Applied Microbiology 2006; 102(4): 1010-1017.

\section{FIGURES AND TABLES}

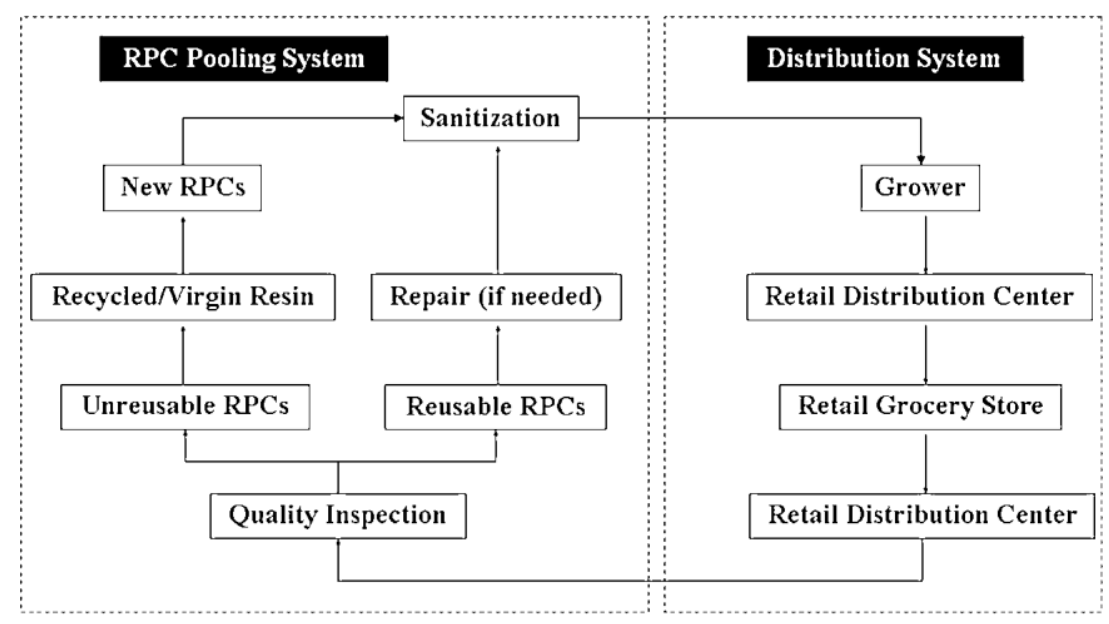

Figure 1. Typical RPC pooling and distribution. 


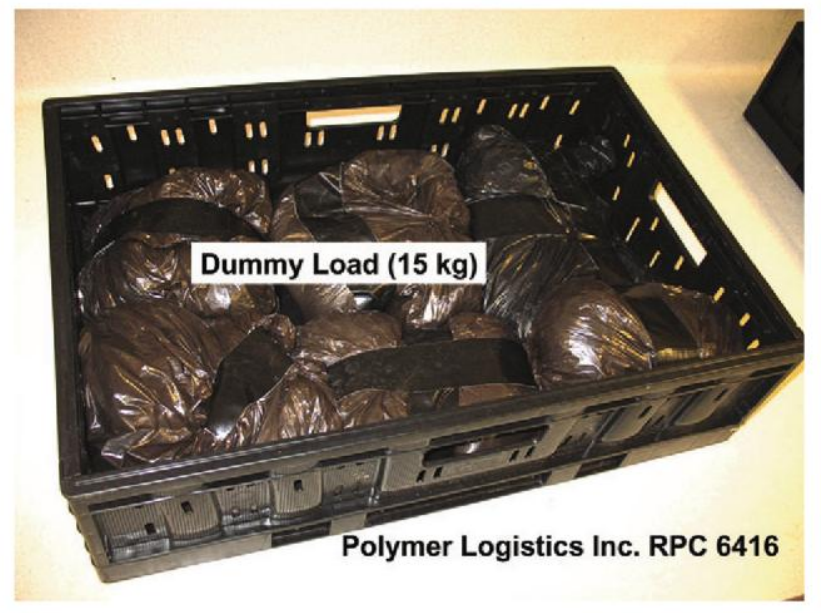

Figure 2. RPC, model 6416.
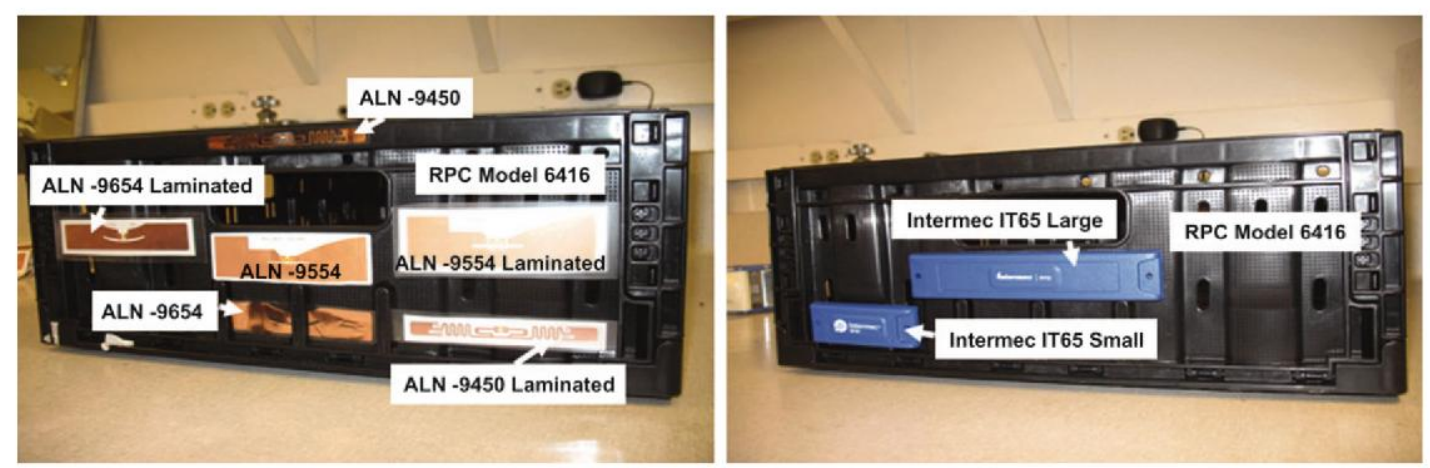

Figure 3. RFID tag placement on RPCs. 




Figure 4. Portal setup.



Figure 5. Test protocol used for each cycle. 


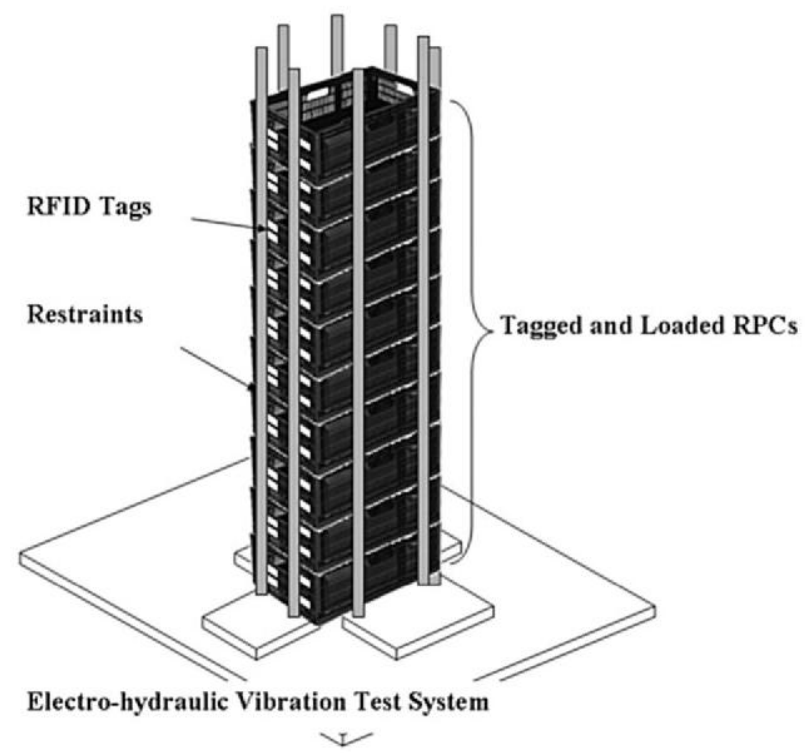

Figure 6. Vibration test setup. 
Table 1. Summary of survival data for all tags tested.

\begin{tabular}{|c|c|c|c|c|c|c|c|c|c|c|c|c|}
\hline \multirow[b]{2}{*}{ PN } & \multirow[b]{2}{*}{$n$} & \multirow{2}{*}{$\begin{array}{c}\text { Pre- } \\
\text { test }\end{array}$} & \multicolumn{2}{|c|}{ Cycle 1} & \multicolumn{2}{|c|}{ Cycle 2} & \multicolumn{2}{|c|}{ Cycle 3} & \multicolumn{2}{|c|}{ Cycle 4} & \multicolumn{2}{|c|}{ Cycle 5} \\
\hline & & & Dist. & Sanit. & Dist. & Sanit. & Dist. & Sanit. & Dist. & Sanit. & Dist. & Sanit. \\
\hline \multicolumn{13}{|l|}{ Encapsulated } \\
\hline Intermec IT65 L & 10 & 10 & 10 & 10 & 10 & 10 & 10 & 10 & 10 & 10 & 10 & 10 \\
\hline Intermec IT65 S & 10 & 10 & 10 & 10 & 10 & 10 & 10 & 10 & 10 & 10 & 10 & 10 \\
\hline \multicolumn{13}{|l|}{ Laminated } \\
\hline ALN 9450 & 10 & 10 & 10 & 10 & 10 & 10 & 10 & 10 & 10 & 10 & 10 & 9 \\
\hline ALN 9554 & 10 & 10 & 10 & 10 & 10 & 10 & 10 & 10 & 10 & 10 & 10 & 10 \\
\hline ALN 9654 & 10 & 10 & 10 & 10 & 10 & 10 & 10 & 10 & 10 & 9 & 9 & 9 \\
\hline \multicolumn{13}{|l|}{ Non-laminated } \\
\hline ALN 9450 & 10 & 10 & 9 & 9 & 9 & 9 & 9 & 7 & 7 & 5 & 5 & 3 \\
\hline ALN 9554 & 10 & 10 & 10 & 9 & 9 & 7 & 6 & 4 & 4 & 4 & 4 & 2 \\
\hline ALN 9654 & 10 & 10 & 10 & 10 & 10 & 8 & 8 & 5 & 5 & 4 & 4 & 2 \\
\hline \multicolumn{13}{|c|}{ b. Tags successfully adhering to the RPCs } \\
\hline \multirow[b]{2}{*}{ PN } & \multirow[b]{2}{*}{$n$} & \multirow{2}{*}{$\begin{array}{l}\text { Pre- } \\
\text { Test }\end{array}$} & \multicolumn{2}{|c|}{ Cycle 1} & \multicolumn{2}{|c|}{ Cycle 2} & \multicolumn{2}{|c|}{ Cycle 3} & \multicolumn{2}{|c|}{ Cycle 4} & \multicolumn{2}{|c|}{ Cycle 5} \\
\hline & & & Dist. & Sanit. & Dist. & Sanit. & Dist. & Sanit. & Dist. & Sanit. & Dist. & Sanit. \\
\hline \multicolumn{13}{|l|}{ Encapsulated } \\
\hline Intermec IT65 L & 10 & 10 & 10 & 10 & 10 & 10 & 10 & 10 & 10 & 10 & 10 & 10 \\
\hline Intermec IT65 S & 10 & 10 & 10 & 10 & 10 & 10 & 10 & 10 & 10 & 10 & 10 & 10 \\
\hline \multicolumn{13}{|l|}{ Laminated } \\
\hline ALN 9450 & 10 & 10 & 10 & 10 & 10 & 10 & 10 & 10 & 10 & 10 & 10 & 10 \\
\hline ALN 9554 & 10 & 10 & 10 & 10 & 10 & 10 & 10 & 10 & 10 & 10 & 10 & 10 \\
\hline ALN 9654 & 10 & 10 & 10 & 10 & 10 & 10 & 10 & 10 & 10 & 10 & 10 & 10 \\
\hline \multicolumn{13}{|l|}{ Non-laminated } \\
\hline ALN 9450 & 10 & 10 & 9 & 9 & 9 & 9 & 9 & 8 & 8 & 5 & 5 & 3 \\
\hline ALN 9554 & 10 & 10 & 10 & 10 & 10 & 10 & 10 & 7 & 7 & 4 & 4 & 2 \\
\hline ALN 9654 & 10 & 10 & 10 & 10 & 10 & 10 & 10 & 9 & 9 & 5 & 5 & 2 \\
\hline
\end{tabular}

Note: Highlighted cells indicate the number of read failures or lost tags. The cells marked in bold are instances where readability first failed after distribution simulation as opposed to after sanitization stress.

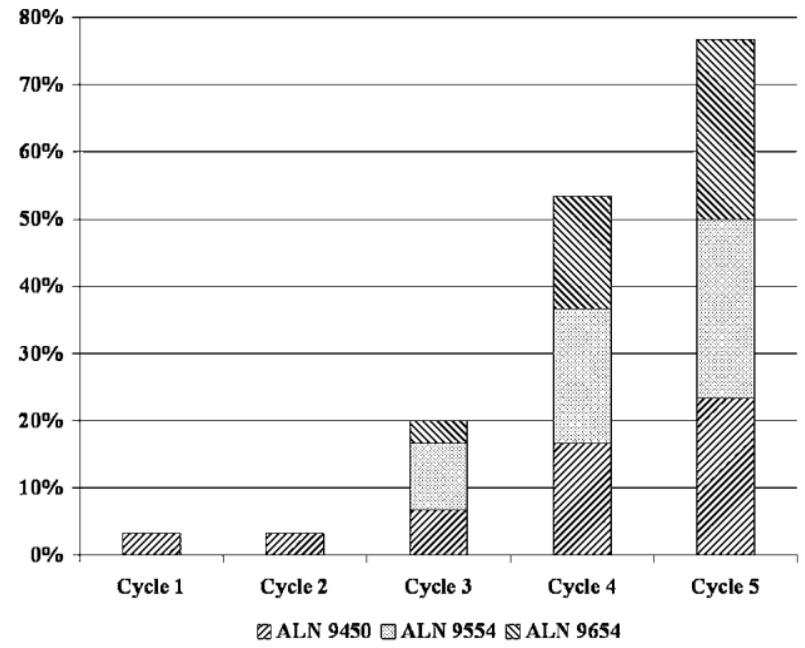

Figure 7. Cumulative lost tag failure percentage for non-laminated tags $(n=30)$. 
Table 2. Cumulative read failure percentage for laminated tags.

\begin{tabular}{lccccc}
\hline & Cycle 1 & Cycle 2 & Cycle 3 & Cycle 4 & Cycle 5 \\
\hline ALN 9450 L & 0 & 0 & 0 & 0 & 3.30 \\
ALN 9554 L & 0 & 0 & 0 & 0 & 0 \\
ALN 9654 L & 0 & 0 & 0 & 3.30 & 3.30 \\
Total & 0.00 & 0.00 & 0.00 & 3.30 & 6.70 \\
\hline
\end{tabular}

Table 3. Cumulative read failure percentage for remaining non-laminated tags.

\begin{tabular}{lccccc}
\hline & Cycle 1 & Cycle 2 & Cycle 3 & Cycle 4 & Cycle 5 \\
\hline ALN 9450 & 0 & 0 & 0 & 0 & 0 \\
ALN 9554 & 3.40 & 10.3 & 12.5 & 0 & 0 \\
ALN 9654 & 0 & 6.90 & 16.7 & 7.10 & 0 \\
Remaining (n) & 29 & 29 & 24 & 14 & 2 \\
Total & 3.40 & 17.2 & 33.3 & 7.10 & 0.00 \\
\hline
\end{tabular}

